\title{
Minimizing Pest and Disease Risks in Uncertain Climates: CABI Initiatives Developing New Technologies and Tools for Outreaching Early Warning to Farmers
}

\author{
Bryony Taylor ${ }^{1 *}$, Jonathan Casey ${ }^{2}$, Sivapragasam Annamalai ${ }^{3}$, Elizabeth A. Finch ${ }^{1}$, Tim Beale ${ }^{2}$, \\ William Holland ${ }^{2}$, Sean T. Murphy ${ }^{1}$, Cambria Finegold ${ }^{2}$ \\ ${ }^{1}$ CABI, Bakeham Lane, Egham, Surrey, TW20 9TY UK \\ ${ }^{2} C A B I$, Nosworthy Way, Wallingford, Oxfordshire, OX10 8DE \\ ${ }^{3} \mathrm{CABI}, 43400$ Seri Kembangan, Selangor, Malaysia \\ *Corresponding author: b.taylor@cabi.org
}

\begin{abstract}
Recent climate models have projected a global temperature increase of at least $1.5-2^{\circ} \mathrm{C}$ on present day temperatures, including a high likelihood of an increase in extreme temperatures experienced in inhabited places. Changes to observed precipitation patterns are likely with several regions predicted to experience an increase in heavy precipitation and others likely to experience more drought, and a precipitation deficit. There is a growing body of evidence to suggest these changing climatic conditions affect the distribution and phenology of pests and diseases of agriculture. As ectothermic organisms, arthropod pests and fungal diseases are sensitive to changes in mean temperatures and temperature ranges to which they are exposed, with warmer average conditions likely to increase development rates and more extreme temperatures likely to have a negative impact on development. Models which incorporate climate change projections indicate that pests and diseases may shift or increase their ranges in line with warming temperatures.
\end{abstract}

Smallholder farmers are particularly vulnerable to the effects of climate change, with farmers reporting negative impacts on crop production and needing to change farming practices in response to changing climates. In the face of changeable conditions, traditional pest management practices may not be as effective given the climate change induced changes which may be present in the ecosystems e.g. alteration of tritrophic interactions between pest and natural enemies.

This paper gives an overview of current and recent projects where $\mathrm{CABI}$ and partners have developed and utilised existing technologies, methodologies and approaches that may help smallholder farmers to receive the necessary information to control pests and diseases in the context of changing climates. First, we cover the application of species distribution models and their benefits in highlighting areas at risk of pest incursion in the future. Second, we cover within season modelling approaches, driven by earth observation data sources to help farmers to make informed decisions on the best time to apply an intervention, in the face of changing within season temperatures. Finally, we report on CABI's activities associated with climate smart agriculture in South East Asia.

Keywords: Climate smart agriculture; early warning system; climate change; species distribution modelling; pest risk; farmer outreach 


\section{Introduction}

Climate change is projected to lead to increases in average temperatures during the day and night in most places across the world by 2050, as well as changing the patterns of seasonal weather. It is also forecasted to lead to the increased frequency and severity of extreme temperatures and weather events including droughts, floods, frosts, heatwaves, and cyclones (IPCC, 2014).

Such changes present increased threats in agriculture. Farmers will face increasingly challenging and unpredictable growing conditions, as well as increased exposure and sensitivity to natural hazards and climatic shocks in many areas (Global Centre on Adaptation, 2020). Yield reductions attributable to climate change of $21 \%$ since the 1960 s have already been observed (Ortiz-Bobea, et al., 2021). Future projections for yield reductions of example key crops include $68 \%$ decrease in bean crop production under high-emissions scenarios (IPCC, 2014), areas suitable for growing coffee are projected to halve by 2050 (Watts, 2016), and while maize yields across much of Africa and Asia could plummet by over 20\% by 2050 (Global Commission on Adaptation, 2018).

Moreover, climate change is expected to drive changes in the distribution of invasive pests and weeds, particularly poleward, and may weaken plant and ecosystem resilience attack from associated pathogens (MacFadyen et al., 2018; Heeb et al., 2017; Heeb et al., 2019; Cavicchioli, et al., 2019; Pyšek, et al., 2020; FAO, 2020; IPPC, 2021). Climate change is also altering ecosystems, changing pests' life cycles and creating new niches where pests and plant diseases can thrive (IPPC, 2019).

Ultimately, the dynamics of the relationships between pests, transmission vectors, plants, soil, habitats, and natural enemies may fundamentally change (IPCC, 2014). This is likely to be true even under best-case scenario low-emissions pathways which limit warming to $1.5^{\circ} \mathrm{C}$, as there will still be significant biodiversity losses and landscape degradation as a result (IPCC, 2018).

Consequently, the ability to provide advice and information on pest risks will become increasingly important under all future climate scenarios, as the models of the past will need to adapt to the changing realities of pest risks, and traditional pest management practices and control products may no longer be as effective (Castex et al., 2018). In particular, early warning systems (EWS) will be crucial tools in alerting farmers and support systems to the impending threats of new and existing pests, while horizon-scanning tools will play an important role in helping predict the likely spread of pests into new habitats.

The International Plant Protection Convention (IPPC) 2020-2030 Strategic Framework recognises the interrelated physical risks posed by climate change and invasive species in agriculture and forestry (FAO, 2020). It notes that the IPPC has not given due consideration to the interrelated nature of climate change and plant health to date, but sets out a plan to address this over the coming ten years. This will include the following measures:

- A higher level of cooperation with relevant international organizations with regard to climate change and capacity building, to ensure that evaluations of climate change impacts incorporate pest related impacts;

- Ensuring pest management guidelines value and enhance ecosystem services and do not negatively impact GHG emissions mitigation actions or the resilience of the ecosystem to climate change hazards; 
- Engagement with international climate change bodies, such as the UNFCCC, IPCC, Green Climate Fund, and Global Environment Facility to share adaptation strategies for responding to the impacts of climate change and mainstream phytosanitary policies into climate change policies;

- Establish a forum for the systematic analysis and discussion of climate change and plant health threats.

In 2021, the IPPC produced a guidance note on plant health and climate change, summarising the interlinkages between pest and disease risks, and physical climate change hazards (IPPC, 2021a). It highlights that climate change increases the risk of pests and diseases to find favourable climate conditions in areas previously uninhabitable to them and consequently spread to these areas. It also notes that pest and disease risks can undermine climate adaptation and mitigation efforts, particularly by causing tree mortality and land degradation.

Preparations are currently underway to determine the post-2020 Global Biodiversity Framework (CBD, 2020), expected to be agreed at the CBD COP15 in China in 2021, after which national governments are likely to begin to prepare new National Biodiversity Strategies and Action Plans (NBSAPs), or similar national policies, which are likely to include targets for managing invasive species and links to climate adaptation actions.

Moreover, governments are also preparing National Adaptation Plans (NAPs) in response to climate change hazards. Fifty-two countries have now had NAP 'readiness support' funding approved by the Green Climate Fund (GCF) (GCF, GCF Support for NAPs, 2020), so NAP planning activities are expected to increase in the coming months and years. There are a range of potential opportunities and benefits to linking and aligning adaptation plans and invasive species management plans, including EWS technologies, agricultural extension and advisory services, locally-led land-use planning, and crop protection and management practices (Casey, 2021).

Given the likelihood of increased threats to agriculture from pest and disease risks exacerbated by climate change, farmers face a number of challenges. These include: a paucity of information on how climate change and pest and disease risks are likely to change in the near-term and in the future in their area; a need for advance warning to take early action to respond to dynamic pest threats; safe and effective plant health products which are effective in future climate scenarios; and techniques and technologies to adapt to climate and invasive species risks. CABI, through a range of initiatives and partners, have been working towards helping farmers to mitigate against the effects of climate change and pest risks. This paper outlines the tools and technologies that $\mathrm{CABI}$ and associated partners have developed over recent years, including a range of pioneering monitoring, surveillance, and early warning technologies and communications systems. 


\section{Tools and technologies that may help governments and regional agencies adapt to the effects of climate change on pest and disease risks}

The expected changes in pest, disease and weed distribution in relation to climate change, highlight the importance of pest risk analysis protocols such as those which form part of the "Stage 2: Pest Risk Assessment" process outlined by the IPPC in the International Standards for Phytosanitary Measures (FAO, 2017). One method for assessing pest and disease risk on a broad geographic scale is through the use of species distribution models (SDMs), also referred to as environmental or ecological niche models. SDMs are tools which are used to predict geographic areas that are likely to be environmentally suitable for a species to survive. The environment, in most cases of modelling, is represented by climate data such as temperature and precipitation, but information on altitude, soil, and land cover can also be used to improve models. Outputs from SDMs can form a key part of a species risk assessment. There are a number of different SDM techniques designed to suit different organisms, but there are two main approaches, correlative modelling and mechanistic modelling. Correlative SDMs establish a statistical relationship between environmental parameters and species occurrences. This relationship is then extrapolated in order to identify areas outside of the species' existing range which may be environmentally suitable. Mechanistic SDMs, on the other hand, explicitly links a species' physiological responses to environmental conditions and uses this to define environmentally suitable geographic areas. Mechanistic models require a detailed knowledge of a species physical response to, and tolerance of environmental conditions. For example, the minimum and maximum temperatures that a species can survive. In many cases, this data is not available and so more common are correlative models which assume that a species' current distribution is a good indicator of a species' environmental requirements.

Once an SDM has been produced based on present-day observations and environmental data, the model can be re-run using datasets which detail potential future climate change scenarios. This can provide an indication of how a species distribution might change alongside changing environmental conditions (Kriticos et al., 2011). This is an important tool for predicting how pest and disease distributions may change in future and help inform governments of future pest risk in the context of climate change. An example of this is a project which CABI collaborated on that used CLIMEX, a mechanistic species distribution modelling tool, to predict the potential distribution of the brown marmorated stink bug, Halyomorpha halys, in Switzerland under a future climate change scenario (Stoeckli et al. 2020). The results from this project provided important information which decision makers can use to assess the risk of further invasion across the country under present but also future conditions. This will allow them to adjust current monitoring programmes and develop sustainable management strategies for the future. As well as modelling pest and diseases, SDMs can also be used to highlight areas which are environmentally suitable, both now and in the future, for the release of biological control agents such as parasitoids. This is evidenced in a CABI collaborative project focussing on Peristenus digoneutis, a parasitoid of Lygus species, important pests of glasshouse and field crops throughout Europe and North America (Olfert et al. 2016). Knowledge of the effect of climate change on this parasitoid is vital information for the maintenance and development of management strategies which are sustainable under a changing climate.

Species Distribution Models however, do have their limitations. Accuracy of SDMs is highly dependent on the quality of input data. Small data samples of known occurrences which aren't representative of different areas where a species exists can lead to an underestimate of a species potential distribution. Conversely, an SDM built only on climate data may overestimate a species potential range where other factors such as land use, host availability and natural enemies are not considered. SDMs are also not effective where the observed species range is not at equilibrium. For example, if a species has been 
recently introduced and is actively expanding its range. Further, SDMs using climate change scenarios are often not capable of accounting for climate impacts on other variables that impact species distribution, such as host plants, soil conditions, landscape degradation, and biodiversity loss. They also do not account for any potential adaptation measures used by farmers or other groups to respond to climate risks, which may involve changes to local ecologies, crops cultivated, and natural resource management; all of which may affect the potential range of endemic and alien pests in a given locality. Despite these limitations, when used in conjunction with other tools, SDMs can be an important and complementary method for analysing the current and future risk of pest and diseases.

Another tool available to assess future pest risk is the CABI Horizon Scanning Tool, which is a decision support aid that helps users identify and categorize species that might enter a particular geographic area from another geographic area. The tool uses CABI distribution data to generate a list of species that are absent from a selected 'area at risk' but present in 'source areas'. 'Source areas' may be chosen because they are neighbouring countries, are linked by trade, or share similar climates. Geographic areas defined at country and sub-national level are matched against Köppen-Geiger climate classifications. Searches can be performed to filter species that are present in a 'source area' which may be able to establish on the basis of sharing similar environmental conditions to part of the 'area at risk'.

The list of species can be further filtered using various criteria (e.g. pathways, habitats and taxonomy) to focus on sets of potential invasive species that may require more detailed risk assessment, surveillance, public awareness or direct action to prevent their introduction and spread. The tool aims to support risk assessors, plant protection officers, quarantine officers, protected area managers and researchers as a quick and user-friendly means of accessing a large volume of relevant data for categorizing and prioritizing potential invasive species. One area of development under consideration is to include future climate scenario classifications, such as those developed by Beck et al. (2018) to add support for longer term horizon scanning.

\section{Tools and technologies that may help farmers enhance resilience to the effects of changing climates}

Shocks to an agricultural system such as those which can be exacerbated by climate change - including pest and disease outbreaks and extreme weather events - can render smallholder farmers extremely vulnerable due to their reliance on agriculture for their livelihoods and own food intake (Harvey et al. 2014). Sixty per cent of farmland in South Asia and 65\% in East Asia is rainfed. As such, the climatic and environmental conditions affecting a given area are extremely important factors for farmers to consider when growing crops, notably more so in rural low-income areas (Coordination SUD, 2015). Smallholder farmers often develop planting patterns and farming calendars based on historical knowledge passed down over generations, however, such practices are now being threatened due to changing rainfall patterns and shifting seasons as a result of climate change. Cropping seasons and planting schedules no longer match seasonal rainfall distributions and therefore impact farmers effectiveness at combating negative impacts such as pest and disease infestations (Becker-Reshef et al., 2019).

There are several ways to help to reduce sensitivity and vulnerability to these risks, including improved access to timely and relevant information, access to credit and insurance services, and policy to safeguard natural ecosystems (Harvey et al., 2014).

Weather-based EWS are crucial tools for farmers to assess the risk of upcoming seasonal conditions and make better-informed decisions to protect their crops and livelihoods. The timeliness of communicating forecast information to farmers is key to combating pest and disease outbreaks. There have been numerous cases of successful community-based EWS being deployed in Asian countries, a 
region that often experiences unpredictable and severe weather conditions. For example, systems supported by ICIMOD (Bicknell, et al., 2020; UNDP,2020) and Practical Action (Budimir, 2020) respectively have combined innovative, low-cost sensor technologies with a community-led communication and response systems.

Many of these systems have been based on people-centred recommendations by the United Nations International Strategy for Disaster Reduction Platform for the Promotion of Early Warning (ISDR, 2006). The key elements are knowledge and monitoring of the risk, warning services, dissemination of risk, and response plans (Macherera and Chimbari, 2016). Early warning systems are not designed to be the sole mechanism to avoid losses in agricultural productivity in the face of changing climates. However, EWS can be vital tools in enhancing the resilience and adaptive capacity of farmers who experience changing conditions season upon season.

Within $\mathrm{CABI}$, projects which aim to provide early warning messages to farmers and key stakeholders, cover both aspects of modelling to create suitable messaging for end users, but also ensure these messages can be disseminated to those who need it so preventative action can be taken.

Many pests and diseases of agricultural crops are either ectothermic organisms (insects and fungal diseases) or vectored by ectothermic organisms (plant viruses vectored by insects). As ectotherms, regulation of body temperature relies on external sources including sunlight and ambient temperature. In general, higher temperatures are associated with faster development (within an optimum range) and may be associated with outbreaks of agricultural pests (Quinn, 2017). Temperature is thus key factor for the prediction of the timing of pest outbreaks.

The Pest Risk Information SErvice (PRISE) is a project led by CABI in association with Assimila, Centre for Environmental Data Analysis (CEDA) and local partners in the four countries of operation (www.PRISE.org). The project has been developing models which give geo- and time-specific risks to crop health for a selection of insects and diseases affecting mixed maize growing systems in Africa, based on environmental data. The outputs of the models give an advance alert for an optimal timeframe for farmers to take action, based on the temperature conditions which have been experienced by the crop/pest that season. These outputs are turned into clear and actionable advisories, which assist end-users with decision-making under variable growing conditions. Different early warning outputs are provided to key user groups including smallholder farmers, advisory services, and national agencies in including National Plant Protection Offices (NPPOs).

The main driver of models in the PRISE system is temperature data which is sourced from near real time weather forecasts (ECMWF) and also an 18-year ERA 5 climatology dataset. These datasets are global and models can theoretically be applied in any location, given the relevant local calibration and validation factors.

A similar approach has been taken by another project managed by CABI "Enabling safe and climate smart coffee production in Colombia", in association with Assimila, Café Export and Climate Edge. The coffee berry borer (CBB) (Hypothenemus hampeii) is the most serious coffee pest worldwide, causing crop damage in excess of US\$500 million annually. Climate change is exacerbating the impact of CBB with studies indicating that for every $1^{\circ} \mathrm{C}$ increase in temperature the intrinsic rate of increase of the pest will increase by $8.5 \%$ as well as facilitating the range expansion of CBB to higher altitudes (Jaramillo et al. 2009). In Colombia, CBB levels have tripled since 2017. Increasing temperatures compounded with a predicted drop in arabica coffee yield associated with a rise of $1^{\circ} \mathrm{C}$ (Craparo et al., 2015) highlight the importance of climate-smart pest management practises. 
Using an innovative combination of remote-sensing technology, satellite earth observation data, and historic climate data, $\mathrm{CABI}$ and its partners are working to develop a pioneering pest alert system to inform institutions via an online data dashboard, and farmers via SMS alerts, when they can expect a CBB surge, enabling them to take appropriate management actions and apply biopesticides at the most effective time.

An important aspect of projects implemented by $C A B I$ and partners, is ensuring that timely, clear and implementable extension advice is disseminated to and understood by farmers. This holistic end-end approach ensures that information is received by those who need it most. Through the CABI led PRISE project early warning pest alerts have been integrated into extension sector messaging services within Kenya, Ghana, Malawi and Zambia. By adopting the pest risk forecast into existing national-level services with their history and experience at communicating agricultural information to rural farming communities, the PRISE early warning service is providing time-sensitive supplementary decision support recommendations direct to farmers. The pest risk forecasts produced by the PRISE project have also been formatted into a bulletin-style report which is sent out to agricultural extension officers under the Plantwise programme on a bi-monthly basis. The PRISE bulletins contain pest risk forecasts converted into maps for national-scaled interpretation, which can be disaggregated to county and district levels. To support the forecasts and subsequent bulletins as a decision support tool, pest management recommendations in the form of cultural and chemical advice is included on all PRISE pests along with rainfall forecasts for the cropping period. Extension services have the capability to take pest and disease early warning information and formulate advice based on local factors, for example, locally utilised cultivars, making the information disseminated to smallholder farmers more realistic, effective and more likely to result in reduced negative impacts from climate change factors. Throughout the PRISE programme, monitoring and evaluation activities have gauged how well information has been received by farmers. The latest data has shown that $>89 \%$ surveyed believed the suggested time to action by EW models is correct (unpublished data) and previous studies have shown that farmers have changed their practices in line with message recommendations (Mbugua et al. 2020). Through the project to date PRISE messages have been directly received by $>193,000$ farmers, extension workers and plant doctors.

Underpinning the modelling work outlined above, is access to high quality datasets. Mechanistic models can require detailed data relating to the biology of the pest or disease. The FAIR data principles (Findability, Accessibility, Interoperability, and Reusability) provide a framework for scientists to share data with clear access, format and quality guidelines studies which look at the potential impacts of climate change on agricultural pests and diseases. Sutherst et al. (2011) highlighted that the CABI Crop Protection Compendium (http://www.cabi.org/compendia/cpc/), and more recently, the CABI Invasive Species Compendium (ISC) which is an open access resource, are useful starting points for collecting such data. Bebber et al. (2013) used data collected through CABI Distribution Maps of Plant Diseases (DMPD) and Distribution Maps of Plant Pests (DMPP) to demonstrate an average poleward shift of plant pathogens and pests of $2.7 \pm 0.8 \mathrm{~km}$ yr-1 since 1960 . More recently, given the importance of open and FAIR data, CABI has started to publish datasets from research in the CABI Data Repository (https://ckan.cabi.org/data). Access to open and FAIR data is vital for the application of modelling and can contribute to our understanding of climate related changes observed in biotic communities. For example, open data published on Fall armyworm observations by Rwomushana et al. (2018) have been used by researchers to look at the current and potential future distribution of plant pests and disease (Early et al. 2018) and have the potential to guide future research in other regions of interest. 


\section{Climate smart pest management}

Measures to ensure the enhancement of ecosystem services and a recognition that pest management practices do not negatively impact the resilience of ecosystems are included in the IPPC 2020-2030 Strategic Framework (FAO, 2020). CABI has developed an approach to invasive species management which aims to ensure climate resilience and mitigation outcomes are achieved as co-benefits of pest management approaches. Climate-smart pest management (CSPM) is a cross-sectoral approach that aims to reduce pest-induced crop losses, enhance ecosystem services, reduce greenhouse gas emissions and strengthen the resilience of agricultural systems in the face of climate change (Heeb, et al., 2019). Through the CSPM approach, farmers will have the information and tools to put into action practices (e.g. crop diversification, establishment of natural habitats, careful water management) that will enhance the health of their farm and surrounding landscape, and reduce its susceptibility to pestinduced disturbance, slow-onset climate hazards and shocks. Building on the Climate Smart Agriculture approach, CSPM aims to achieve the 'triple win' of improved productivity, resilience to climate change, and greenhouse gas mitigation (Heeb, et al., 2017).

An example of where CABI has implemented the CSPM approach is in the Climate Smart Agriculture initiative under the Climate Change for Agriculture and Food Security (CCAFS-CGIAR) program led by IRRI. In three chosen Climate Smart Villages (CSVs) in Vietnam (Tra Hat Village), Cambodia (Rohal Sourng village) and Laos (Ekxang Village), CSPM was amongst the six 'smart' pillars of agricultural activities aimed at addressing risks driven by climate change. Amongst the interventions, $C A B I$ established community-based 'plant clinics' modelled after the CABI-led Plantwise programme (https://www.plantwise.org/), to gather early warning information on pest and disease incidences and to disseminate plant health advice to farmers using 'plant doctors' and mobile services. Other techniques included integrated pest/crop management (IPM/ICM) practices and use of environmentfriendly ecological engineering, which included teaching farmers on effective means of attracting natural enemies in the field.

\section{Conclusion}

This paper has demonstrated a number of ways in which $C A B I$ is responding to the growing impacts of climate change on pest and disease risks for smallholder farmers across low-income countries worldwide, and which have the potential to be applied or utilised in the Asian and Pacific Region. By supporting farmers with a range of tools, technologies, and techniques which can help identify threats early, respond dynamically to changing meteorological and seasonal conditions, and cultivate crops through more affordable, sustainable, and climate-smart approaches, CABI has demonstrated how smallholder farmers can effectively adapt to climate change impacts and maintain food production.

The combination of these approaches, which address the multiple challenges of timely, actionable information, and resilient farming, help to overcome some of the challenges often associated with pest risk advisory services, and ensure agricultural systems can continue to function even under future climate scenarios.

However, many challenges remain. In particular, equity in access to climate and pest advisory services, and in realising the benefits of such advice, are crucial issues to address. Socio-cultural norms and practices which determine power relations may facilitate or restrict access to information for individuals or groups. For example, certain individuals or groups may be prevented from learning about the service, attending meetings and trainings, from interacting with unfamiliar people of other gender or ethnic groups, owning digital devices, or acting upon the information received due to disapproval from family or community members. Equity of access to information does not provide 
equity of outcome. An individual's ability to use and benefit from a climate advisory service is dependent upon their level of literacy and numeracy, their access to finance, land and labour, their power and control over the decision-making process, confidence level, and experience (Staub, Clarkson, Fara, Casey, 2021 [forthcoming]).

Advisory services and EWS should be designed in a way that different stakeholders are involved at each stage of the process from design through to implementation, learning and improvement. Such an approach can help to foster the ownership, legitimacy and sustainability of a service. As advisory services and EWS seek greater financial sustainability, a critical issue will be in ensuring that the poorest and most marginalised farmers are not 'left behind' if unable to pay for the services.

The ability to scale these approaches to wider regions and millions more smallholder farmers is also a major issue for these and other monitoring and EWS. Although such services have proven effective to date, they are not yet financially self-sustaining and rely on international donor support. Moreover, their effectiveness is built on trusted relationships in each area of operation, and the tailoring of the systems and information to local needs, including ensuring advisory services and early warning messages are communicated in the languages spoken by users in each region. Scaling these approaches to many more countries in localities requires a significant investment to ensure they are locally-led and responsive to local needs as possible.

One approach to improving buy-in for the development and deployment of such climate-smart pest risk management services is to ensure that they are integrated into national plans. A recent review of national climate change and invasive species management policies in four countries in Asia and Africa found that there was generally very little integration of approaches to managing associated risks, despite response actions and governance systems usually involving the same actors and organisations, and even employing similar management practices (Casey, 2021). Although these two issues of biotic and abiotic stresses both pose serious threats now and in the future to food security, ecosystem integrity, and water availability for the same stakeholders - particularly smallholder farmers - they are treated as separate issues in current policy and donor-supported programmes.

As countries look to develop new biodiversity action plans, and submit enhanced climate action plans to meet Paris Agreement goals, there is an opportunity for more coordinated policy approaches and implementation strategies for these two intrinsically linked areas of natural resources management. The greatest area of potential for technical interlinkages lies in the development and promotion of EWS (Casey, 2021). In national policies, these are primarily focused on weather-related extreme events (flooding, drought, cyclones, and landslides), but there is scope to extend this to pest and disease outbreaks, and to address the root-causes of climate vulnerability which exacerbate risks, such as invasive plants depleting water availability and destabilising soils.

Given both Invasive species management (ISM) and climate adaptation issues and solutions are both highly variable and context-dependent, the focus on coordinated action at the meso-level of governance appears to be a 'sweet spot' for integrated planning and action (Visseren-Hamakers, et al., 2021). The need to value local perspective in invasive species management and climate adaptation is crucial to developing appropriate strategies which minimize trade-offs (Tebboth, Few, Assen, \& Degefu, 2020). Approaches supporting local governance would align well to the recently-launched 'principles of locally-led adaptation' (Soanes, et al., 2021) which have been endorsed by more than 40 governments (IIED, 2021), and the renewed focus on 'nature-based solutions' (NbS) which will be prioritised at COP26 in 2021 (UNFCCC, 2020). Martin et al (2021) found that critical enablers of NbS include coordination across multiple scales of governance, participatory engagement of local stakeholders, and financing community-led implementation of prioritised activities. 


\section{References}

Bebber, D.P., Ramotowski, M.A.T., Gurr. S.J. (2013). Crop Pests and Pathogens Move Polewards in a Warming World. Nature Climate Change 3(11):985-88. doi: 10.1038/nclimate1990.

Beck, H. E., Zimmermann, N. E., McVicar, T. R., Vergopolan, N., Berg, A., Wood, E. F. (2018). Present and future Köppen-Geiger climate classification maps at 1-km resolution. Scientific Data, 5(1). https://doi.org/10.1038/sdata.2018.214

Bicknell, D., Narlock, C., Rambert, R. (2020). Community Based Flood Early Warning Systems Improving Climate Change Adaptation in the Hindu Kush Himalayan Region. Cambridge, MA: Harvard Kennedy School. Retrieved from https://www.belfercenter.org/sites/default/files/files/publication/Policy\%20Brief-

Community\%20Based\%20Flood\%20Early\%20Warning\%20Systems\%20-

\%20Bicknell\%2c\%20Narlock\%2c\%20Rambert.pdf

Budimir, M. (2020). Practical Action and Early Warning Systems. Rugby, UK: Practical Action Publishing. Retrieved from https://practicalaction.org/knowledge-centre/resources/practical-action-and-earlywarning-systems/

Casey, J. P. (2021). Policy coherence for national climate change adaptation and invasive species management in four countries. Agrirxiv. doi:10.31220/agriRxiv.2021.00055

Cavicchioli, R., Ripple, W. J., Webster, N. S. (2019). Scientists' warning to humanity: microorganisms and climate change. Nature Reviews Microbiology, 17, 569-586. doi:https://doi.org/10.1038/s41579019-0222-5

CBD. (2020). Preparation of the post-2020 global biodiversity framework: conclusions of the Work Group. Montreal: CBD. Retrieved from https://www.cbd.int/doc/recommendations/wg202002/wg2020-02-rec-01-en.pdf

Craparo, A. C. W., P. J. A. Van Asten, P. Läderach, L. T. P. Jassogne, Grab, S. W. (2015). Coffea arabica Yields Decline in Tanzania Due to Climate Change: Global Implications. Agricultural and Forest Meteorology 207:1-10. doi: 10.1016/j.agrformet.2015.03.005.

Early, R, González-Moreno, P., Murphy, S.T., Day, R. (2018). Forecasting the Global Extent of Invasion of the Cereal Pest Spodoptera frugiperda, the Fall Armyworm. NeoBiota 40:25-50. doi: 10.3897/neobiota.40.28165.

FAO. (2017) International Standards for Phytosanitary Measures 11: Pest risk analysis for quarantine pests.

https://assets.ippc.int/static/media/files/publication/en/2019/05/ISPM 112013 En PRA QPs 201 9-04-30 PostCPM14 InkAm.pdf

FAO. (2020). Strategic framework for the International Plant Protection Convention (IPPC) 2020-2030. Rome: FAO. Retrieved from https://assets.ippc.int/static/media/files/publication/en/2020/12/IPPC_Strategic_Framework_20202030_2020-12-09.pdf

GCF (2020). GCF Support for NAPs. Retrieved February 20, 2021, from GCF Readiness Support: https://www.greenclimate.fund/readiness/naps

Global Centre on Adaptation. (2020). State and Trends in Adaptation Report 2020. Global Centre on Adaptation. Retrieved from https://gca.org/reports/state-and-trends-in-adaptation-report-2020/ 
Global Commission on Adaptation. (2018). Feeding The World In A Changing Climate: An Adaptation Roadmap For Agriculture. Retrieved from https://gca.org/wpcontent/uploads/2020/12/18 WP GCA Agriculture 1018.pdf

Harvey, C.A., Rakotobe, Z.L., Rao, N.S., Dave, R., Razafimahatratra, H., Rabarijohn, R.H., Rajaofara, H., MacKinnon, J.L (2014). Extreme Vulnerability of Smallholder Farmers to Agricultural Risks and Climate Change in Madagascar. Philosophical Transactions of the Royal Society B: Biological Sciences 369(1639):20130089. doi: 10.1098/rstb.2013.0089.

Heeb, L., Jenna, E. (2017). Climate-Smart Pest Management: Implementation guidance for policymakers and investors. Rome: FAO. Retrieved from http://www.fao.org/3/BU464EN/bu464en.pdf

Heeb, L., Jenner, E., Cock, M. J. (2019). Climate-smart pest management: building resilience of farms and landscapes to changing pest threats. Journal of Pest Science, 92, 951-969. doi:https://doi.org/10.1007/s10340-019-01083-y

IIED (2021) Principles for locally led adaptation. https://www.iied.org/principles-for-locally-ledadaptation

IPCC (2014). Fifth Assessment Synthesis Report. Retrieved from https://www.ipcc.ch/assessmentreport/ar5/

IPCC (2018). Special Report: Global Warming of $1.5^{\circ} \mathrm{C}$, Summary for Policymakers. Retrieved from https://www.ipcc.ch/site/assets/uploads/sites/2/2019/05/SR15_SPM_version_report_LR.pdf

IPPC (2019). Plant Health and Environmental Protection. Rome: FAO. Retrieved from http://www.fao.org/3/ca3279en/CA3279EN.pdf

IPPC (2021). Plant health and climate change. Rome: FAO. Retrieved from http://www.fao.org/3/cb3764en/cb3764en.pdf

IPPC (2021a). Plant health and climate change. Rome: FAO. Retrieved from http://www.fao.org/3/cb3764en/cb3764en.pdf

ISDR (2006) Developing Early Warning Systems: A checklist. EWC III: Third International Conference on Early Warning: From concept to action. 27-29 March, 2006. Bonn, Germany. https://www.unisdr.org/2006/ppew/info-resources/ewc3/checklist/English.pdf

Jaramillo, J., Chabi-Olaye, A., Kamonjo, C., Jaramillo, A., Vega, F.E., Poehling, H.M., Borgemeister, C. (2009). Thermal Tolerance of the Coffee Berry Borer Hypothenemus hampei: Predictions of Climate Change Impact on a Tropical Insect Pest edited by S. Rands. PLoS ONE 4(8):e6487. doi: 10.1371/journal.pone.0006487.

Macfadyen, S, G McDonald, G., Hill, M.P. (2018). From Species Distributions to Climate Change Adaptation: Knowledge Gaps in Managing Invertebrate Pests in Broad-Acre Grain Crops. Agriculture, Ecosystems \& Environment 253:208-19. doi: 10.1016/j.agee.2016.08.029.

Martin, J.G.C., Scolobig, A., Linnerooth-Bayer, J., Liu, W., Balsiger J. 2021. Catalyzing Innovation: Governance Enablers of Nature-Based Solutions. Sustainability 13(4):1971. doi: $10.3390 /$ su13041971. 
Mbugua, F, Bundi, M., Day, C., Beale, T., Williams, F. (2020). PRISE-PAD Fall Armyworm SMS Alert Pilot Results. 17.

Ortiz-Bobea, A., Ault, T. R., Carrillo, C. M., Chambers, R. M., Lobell, D. B. (2021). Anthropogenic climate change has slowed global agricultural productivity growth. Nature Climate Change, 11, 306-312. doi:https://doi.org/10.1038/s41558-021-01000-1

Olfert, O., Haye, T., Weiss, R., Kriticos, D., Kuhlmann, U. (2016). Modelling the potential impact of climate change on future spatial and temporal patterns of biological control agents: Peristenus digoneutis (Hymenoptera: Braconidae) as a case study. The Canadian Entomologist, 148(5), 579-594. doi:10.4039/tce.2016.4

Pyšek, P., Hulme, P. E., Simberloff, D., Bacher, S., Blackburn, T. M., Carlton, J. T., . Richardson, D. M. (2020). Scientists' warning on invasive alien species. Biological Reviews, 95(6), 1511-1534. doi:https://doi.org/10.1111/brv.12627

Quinn, B.K. (2017). A Critical Review of the Use and Performance of Different Function Types for Modelling Temperature-Dependent Development of Arthropod Larvae. Journal of Thermal Biology 63:65-77. doi: 10.1016/j.jtherbio.2016.11.013.

Rwomushana, I. (2018). Dataset: Fall Armyworm: Impacts and Implications for Africa Data 2018. CABI Datasets. https://doi.org/10.34857/0048168

Soanes, M., Bahadur, A., Shakya, C., Smith, B., Patel, S., Rumbaitis del Rio, C., Coger, T., Dinshaw, A., Patel, S., Huq, S., Rahman, M.M., F, Gupta, S., Dolcemascolo, G., Mann, T. (2021) Principles for locally led adaptation: A call to action. IIED, London. http://pubs.iied.org/10211IIED. ISBN 978-1-78431-8697 Stoeckli, S., Felber, R. Haye, T. (2020) Current distribution and voltinism of the brown marmorated stink bug, Halyomorpha halys, in Switzerland and its response to climate change using a highresolution CLIMEX model. International Journal of Biometeorology 64, 2019-2032 https://doi.org/10.1007/s00484-020-01992-z

Sutherst, R. W., Constable F., Finlay, K.J., Harrington, R., Luck, J., Zalucki, M.P (2011). Adapting to Crop Pest and Pathogen Risks under a Changing Climate. WIREs Climate Change 2(2):220-37. doi: 10.1002/wcc.102.

Tebboth, M.G.L., Few, R., Assen, M., Degefu, M.A. (2020). Valuing local perspectives on invasive species management: Moving beyond the ecosystem service-disservice dichotomy. Ecosystem Services, Elsevier, vol. 42(C). (UNFCCC, 2020)

Visseren-Hamakers, I. J., Razzaque, J., McElwee, P., Turnhout, E., Kelemen, E., Rusch, G. M. (2021). Transformative governance of biodiversity: insights for sustainable development. Current Opinion in Environmental Sustainability, 53, 20-28. doi:https://doi.org/10.1016/j.cosust.2021.06.002

Watts, C. (2016). A Brewing Storm: Climate Change Risks to Coffee. The Climate Institute. Retrieved from https://files.fairtrade.net/publications/2016_TCI_ABrewingStorm.pdf 